\title{
Identifying decision-relevant uncertainties for dynamic adaptive forest management under climate change
}

\author{
Naomi Radke ${ }^{1}$ (D) $\cdot$ Klaus Keller $^{2,3} \cdot$ Rasoul Yousefpour $^{1} \cdot$ Marc Hanewinkel $^{1}$
}

Received: 5 February 2020 / Accepted: 19 October 2020 /Published online: 9 November 2020

(C) The Author(s) 2020

\begin{abstract}
The decision on how to manage a forest under climate change is subject to deep and dynamic uncertainties. The classic approach to analyze this decision adopts a predefined strategy, tests its robustness to uncertainties, but neglects their dynamic nature (i.e., that decision-makers can learn and adjust the strategy). Accounting for learning through dynamic adaptive strategies (DAS) can drastically improve expected performance and robustness to deep uncertainties. The benefits of considering DAS hinge on identifying critical uncertainties and translating them to detectable signposts to signal when to change course. This study advances the DAS approach to forest management as a novel application domain by showcasing methods to identify potential signposts for adaptation on a case study of a classic European beech management strategy in South-West Germany. We analyze the strategy's robustness to uncertainties about model forcings and parameters. We then identify uncertainties that critically impact its economic and ecological performance by confronting a forest growth model with a large sample of timevarying scenarios. The case study results illustrate the potential of designing DAS for forest management and provide insights on key uncertainties and potential signposts. Specifically, economic uncertainties are the main driver of the strategy's robustness and impact the strategy's performance more critically than climate uncertainty. Besides economic metrics, the forest stand's past volume growth is a promising signpost metric. It mirrors the effect of both climatic and model parameter uncertainty. The regular forest inventory and planning cycle provides an ideal basis for adapting a strategy in response to these signposts.
\end{abstract}

Keywords Forest management - Climate change - Deep uncertainties · Global sensitivity analysis · Signposts $\cdot$ Scenario discovery

Supplementary Information The online version contains supplementary material available at https://oi. org/10.1007/s10584-020-02905-0.

Naomi Radke

naomikradke@gmail.com

Extended author information available on the last page of the article 


\section{Introduction}

Decision-makers in forest management face deep and dynamic uncertainties that can influence the success of their forest management strategy, especially under climate change (Seidl et al. 2017; Augustynczik et al. 2017). Deep uncertainty is related to the Knightian definition of uncertainty (Knight 1921) and refers to a situation in which experts do not know or parties involved in the decision cannot agree upon (a potential subset of) (i) a probability distribution of key factors (e.g., how probable different climate change scenarios are) and/or model parameters (e.g., ecosystem models), (ii) the system and its boundaries (what parameters and variables to consider and how they are interacting), and (iii) preferences regarding different outcomes (Lempert et al. 2003). Consequently, decision-makers are able to define plausible scenarios or a set of plausible probability density functions about the uncertain factors, but cannot assign single probabilities to them (Marchau et al. 2019).

The importance of the deep and dynamic uncertainties in forest management is driven, in part, by the long planning horizon in forestry. European beech (Fagus sylvatica) forests, for example, have production times of more than 120 years in Central Europe. During that time, decision-relevant factors can change drastically and the current forest management system might not fit the new conditions anymore. Climatic change is a prominent and broadly researched deep uncertainty that affects forest management (e.g., Augustynczik et al. (2017), Lindner et al. (2014), Millar et al. (2007)). Other uncertainties that are critical to the success of forest management are timber price and discount rate development, change in policies, and stakeholder preferences (Yousefpour et al. 2012). Model parameters pose another source of uncertainty, since parameters may not all be well-known and may vary regionally (Augustynczik et al. 2017). Yet, model parametric uncertainty of forest simulation models receives little attention in climate impact studies even though they can considerably add to overall impact uncertainty (Reyer et al. 2016; Augustynczik et al. 2017).

Deep uncertainties pose nontrivial conceptual challenges and require different decisionanalytical approaches compared to a situation under well-characterized uncertainty (e.g., where a single probability density function can be identified) (Lempert et al. 2003; Marchau et al. 2019; Walker et al. 2001). In forest management studies that focus on decision-making, deeply uncertain factors are commonly represented by a limited amount of scenarios (see Petr et al. (2019) for a review) and as time-independent rather than dynamic factors (e.g., constant discount rates over time) (e.g., Augustynczik et al. (2017)). Improved quantification of these uncertainties can potentially improve the design of forest management strategies. Approaches that analyze decisions under deep uncertainty include robust decision-making (Lempert et al. 2003), many objective robust decision-making (Kasprzyk et al. 2013), dynamic adaptive pathways (Haasnoot et al. 2013), adaptive policy-making (Hamarat et al. 2014), and direct policy search (e.g., Quinn et al. (2017)). These are based on the idea that under deep uncertainty, decisions cannot be optimized for just a best guess of the probability function and the need to consider the robustness to the deep uncertainties. A typical approach to robust decision making is to use system models that simulate the consequences of a strategy. The models are run under a large ensemble of plausible futures to systematically explore the uncertainty space (Kwakkel 2017). This approach provides insights into decision-relevant characteristics such as the robustness of a decision alternative, its vulnerability to failure, and the relative impact of the uncertainties on a strategy's performance. Since these approaches typically require a large number of model runs, the system models have to be computationally nimble in the absence of very large computer allocations (Haasnoot et al. 2015). This typically 
requires the use of empirical (as opposed to highly complex and computationally expensive) forest models. While empirical forest models may lack system processes such as carbon, water, and nutrient cycles compared to process-based forest models (Augustynczik et al. 2017), they are much more computationally efficient and thus a suitable basis for robust decision-making (Trasobares et al. 2016).

In Germany's managed forests, guidelines describe how to manage a forest stand at different stages over the stand's rotation period (e.g., for the state of Baden-Württemberg, see Forst (2014)). Even though these guidelines acknowledge climate change, forest management plans generally do not offer options for adaptation when new information about the system dynamics is learned, e.g., updated climate forecasts. These guidelines are thus static plans that are defined a priori for the entire planning period (e.g., a management plan that suggests a certain stand density at different stand ages) as opposed to dynamic adaptive plans that rather commit to short-term actions and allow adaptation to changing conditions, in order to preserve performance when a critical threshold value is reached (Haasnoot et al. 2015). Adaptive plans do not only react to vulnerabilities but can also seize opportunities to increase performance (Kwakkel and Haasnoot 2019). The application of dynamic rather than static robust decision-making approaches in other fields of natural resources management under climate change has shown that dynamic approaches can considerably increase the performance compared to static approaches (Garner and Keller 2018; Hamarat et al. 2014; Quinn et al. 2017).

A dynamic adaptive strategy (DAS) requires a monitoring system that identifies if and when to change actions. Many adaptive decision analyses identify so-called signposts that are used to trigger actions that either reassess, correct, or defend the basic strategy in order to maintain performance requirements (Haasnoot et al. 2013) or even improve it (Kwakkel and Haasnoot 2019). These signposts are based on critical uncertainties, i.e., uncertainties that strongly affect the success of the policy (Raso et al. 2019). Exploratory modeling (Hamarat et al. 2014), in combination with a global sensitivity analysis, is a highly recommended approach to identify the relative importance of different deep uncertainties on the strategy's performance and thus to focus the monitoring on uncertainties that really matter (Herman et al. 2015; Kwakkel and Haasnoot 2019).

This study provides several key contributions. First, it introduces the use of exploratory modeling for analyzing robustness in performance and identifying potential signposts for adaptive forest management, as a novel application domain. Second, the case study provides insights into the robustness of current management, the decision-relevant uncertainties, and possible signposts. These insights can inform the design of a DAS. Third, it provides a new test case to the research community of decision-making under deep uncertainty.

Specifically, we:

(i) Adapt an empirical, climate-sensitive beech growth model (Trasobares et al. 2016) for application under a classical beech management (Altherr 1971) in South-West Germany, which is based on a deterministic management plan and is thus an example of a static strategy,

(ii) Test the vulnerability of the strategy to uncertainties by simulating stand development under this strategy and under a large ensemble of plausible future pathways and model parameter scenarios,

(iii) Identify which uncertainties most strongly influence the management objectives using global sensitivity analysis (Sobol” 2001), and 
(iv) Suggest potential signpost parameters that can track these critical uncertainties for use in designing a DAS as an alternative to a static strategy.

\section{Methods}

We structure the analysis using the "XLRM framework" (Lempert et al. 2003) (see Fig. 1). The name XLRM represents the four components of the analysis. The decision lever " $L$ " is the management strategy. We evaluate the performance of the management strategy in the face of exogenous uncertainties "X," i.e., factors that a decision-maker cannot control (Knight 1921; Kwakkel 2017). We treat structural uncertainty regarding the beech growth model parameters as an external factor. The strategy's performance is measured using two metrics "M," representing the economic and ecological performance, respectively: (i) the net present value (NPV) from timber production and (ii) the net carbon sequestration in timber and timber products. Relationships " $\mathrm{R}$ " describe how these elements relate to each other. We use a model that simulates beech growth under a given management strategy and under predefined scenarios of uncertain future pathways of climate change, timber price, and discount rate, as well as model parameter uncertainty $(\mathrm{X})$ to calculate the performance metrics $(\mathrm{M})$ under each uncertainty scenario. The performance under each scenario is the basis to calculate the robustness of the strategy and to rank the impact each uncertainty has on the performance. We detail the elements of the XLRM-framework in the following subsections.

\subsection{Growth and management model}

We choose a climate-sensitive, empirical beech growth model for our computationally intensive analysis. We adopt the model developed by Trasobares et al. (2016). It directly integrates climate sensitivity through two variables, both affecting diameter growth, height growth, and mortality: drought index and degree-day index. Both indices are in the range [0,1], where 1 means no limitation of site productivity by the water amount or by temperature while values lower than 0.7 represent negative effects by drought or low temperature (Trasobares et al. 2016).

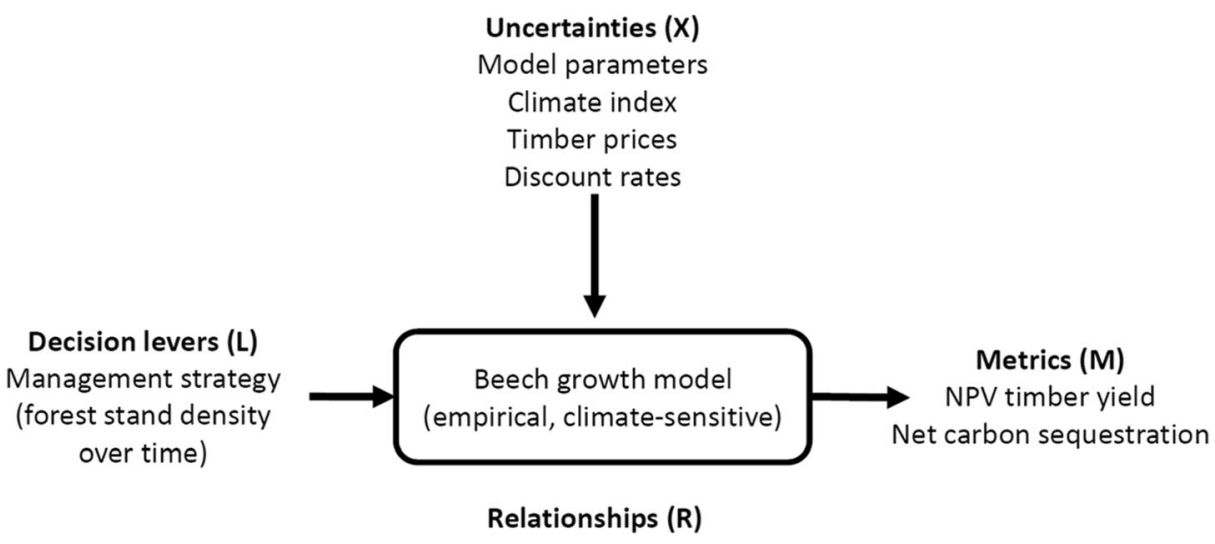

Fig. 1 Analysis flow using an XLRM framework, which specifies the endogenous uncertainties (X), decision levers $(\mathrm{L})$, performance metrics $(\mathrm{M})$, and the relationships $(\mathrm{R})$ used to quantify the performance metrics for the decision levers under given uncertainties 
Both variables can be derived using precipitation and temperature data for the months of AprilOctober. The computation of the drought index additionally requires the water holding capacity (WHC) (for $1 \mathrm{~m}$ of soil depth; $\mathrm{mm}$ ) of the site. Additionally, both climate indices include threshold values that indicate whether site productivity is limited by the WHC or the sum of degree days, respectively. The model is implemented in the $\mathrm{R}$ programming language, is computationally efficient, and given the relative simplicity also rather transparent (see Section 2.1.2 for details). The model simulates tree growth and harvest of even-aged beech trees and aggregates the data at the stand level. The management module offers three different management patterns that define the forest stand's density over time, measured by the basal area $\left(\mathrm{m}^{2} / \mathrm{ha}\right)$, which is the cross-sectional area of trees at breast height ( $1.3 \mathrm{~m}$ above the ground). These three management patterns distinguish themselves by the diameter sizes harvested and that have to be specified for each management event: "High" management removes trees starting with the highest diameter classes and then declines until a desired basal area is reached. "Low" management starts by harvesting trees from the lowest diameter classes and "uniform" management removes trees uniformly over all diameter classes. Trasobares et al. (2016) use data from beech stands all over Switzerland to calibrate the model and also the threshold values for the climate indices, where a WHC $<210 \mathrm{~mm}$ and a sum of degree days (sum of temperature $\left({ }^{\circ} \mathrm{C}\right)$ for days with $>5{ }^{\circ} \mathrm{C}$ daily average, April-October $)<1900$ mean that site productivity is limited. The model requires input initial stand data (diameter distribution per hectare), a management strategy which defines the desired stand density, as well as climate data (6-year averages) for every 5-year period. It is described in detail by Trasobares et al. (2016). We choose a classical beech management (Altherr 1971), which predetermines the stand density over the rotation period by a "basal area curve." Even though it is not practiced anymore rigidly, many elements of current forest practices are taken over from Altherr (1971), especially the promotion of the so-called future crop trees. These crop trees are released by early and intensive removal of the directly competing trees. Additionally, this management has been extensively tested by the Forest Research Institute of Baden-Württemberg (FVA) (Klädtke. J.). As a result, there is a treasure trove of long-term data from test plots in South-West Germany, as described below.

\subsubsection{Adapting the model to the study site}

To check its viability for the study region in South-West Germany, we confront the model with recorded stand and harvest data of a trial plot that applies the management strategy (Altherr 1971) since 1969, provided by the FVA. The model predictions with the original parameter estimates for Switzerland are not satisfying for the case study location (see Fig. 2). They (1) underestimate basal area growth and (2) have a different harvest pattern for a "high" management. We thus calibrate the tree growth and mortality parameters and adapt the "high" management module according to the recorded observational data as described in detail in Online Resource 2.

We fit the model parameters of the diameter and height growth functions and the mortality functions by minimizing the root mean squared error (RMSE) of yearly volume growth per hectare between harvest events for every 5-year period in 1969-2014 using a differential evolution algorithm for global optimization (R-package DEoptim) (Mullen et al. 2011). The optimization algorithm searches between $\pm 5 *$ standard error bounds around the original parameter values (Online Resource 1, Table ESM1). R-code and data for the precalibration and the analyses described below are available at https://github.com/NaomiRadke/robustness_ sensitivity_analysis. 


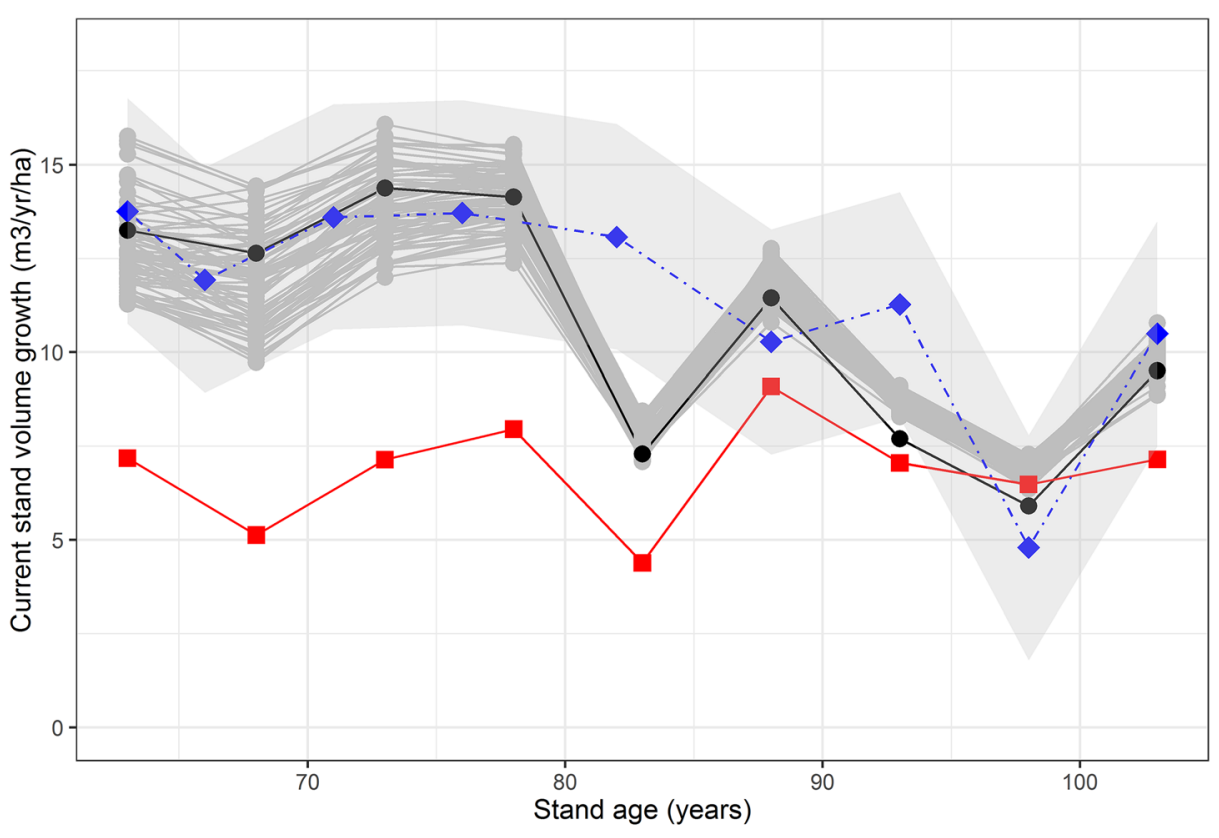

Acceptable range $3 \mathrm{~m} 3 / \mathrm{ha} / \mathrm{yr}$ deviation from observation

Sources - accept. model parameter sets - model best fit - model original parameters

observation

Fig. 2 Current stand volume growth at different stand ages for observed data, best fit model parameters, and 84 other model parameter scenarios with an acceptable deviation from observations

\subsubsection{Management objectives}

We measure the performance of the management strategy using two potentially conflicting objectives: (1) NPV of timber harvest and (2) net carbon sequestration. We focus on two objectives to start with a simple and parsimonious example. There are, of course, additional relevant objectives that can be analyzed using our general framework. However, highdimensional and complex trade-off analysis can lead to complex communication and decision-support challenges (Oprean et al. 2019).

The $N P V_{\text {Timber }}$ is the sum of financial flows from timber production discounted to net present value. The financial flows comprise revenues from selling the timber harvested in each period i.e., the stem volume removed at time t, $V_{t}$, multiplied by market price $P$ net of the harvesting cost $C$. The NPV also takes into account the difference between the value of the initial stand state and the discounted value of the remaining stand at $t=123$ (stand age 123 years) according to:

$$
N P V_{\text {Timber }}=\sum_{t=1}^{T} f_{i t} V_{t}\left(P_{t}-C_{t}\right)-F C+f_{i T} V_{T}\left(P_{T}-C_{\mathrm{T}}\right)-V_{t=0}\left(P_{t=0}-C_{t=0}\right)
$$

where $f_{i t}=\frac{1}{(1+i t)}^{t}$ is the discount factor with the interest rate $i$ at time $t$. The interest rate $i t$ is variable over time (see Section 2.2). We calculate the time-variable net wood prices $\left(P_{t}-C_{t}\right)$ as a function of individual tree diameter, using prices for different assortment classes in Baden- 
Württemberg and diameter-dependent harvest costs by Härtl et al. (2013). We derive a diameter-dependent net price curve by first sorting the tree stems into different assortment classes and industrial wood using the BDATPRO program by the FVA (Kublin and Scharnagel 1988). We then multiply the fractions of each stem that are sorted into specific classes by the respective price and on that basis calculate the revenue of a stem with a specific diameter. We then fit a curve to the revenue-diameter relation. We do not consider planting costs since we start our analysis at an advanced stand age (63 years) and the considered beech tree stand is naturally regenerated (Augustynczik et al. 2017). We deduct fixed costs $(F C)$ of 175 Euro per hectare and year to account for other costs such as administration.

The net carbon storage is the sum of additional carbon sequestration through forest management over a time horizon of 60 years:

$$
\text { Net carbon sequestration }=\sum_{t=1}^{T} \Delta \operatorname{Carb}_{t}
$$

where the additional carbon sequestration in each 5 -year period is the balance between periodic carbon sequestration through above-ground tree biomass growth $g_{t}$ minus periodic emissions from wood product decay $u_{t}$ :

$$
\Delta \operatorname{Carb}_{t}=g_{t}-u_{t}
$$

based on Härtl et al. (2017). Carbon stored in above-ground biomass and wood products is based on the equation adapted from Pistorius et al. (2006):

$$
\left.C a r b=\left[V * D_{s} * V E F\right)\right] * C F
$$

where $V$ is the stem volume, $D_{s}$ is the bulk density of the stem, $V E F$ is the volume expansion factor from stem to total above-ground tree volume, and $\mathrm{CF}$ is the carbon factor (Online Resource 1, Table ESM2). We consider only the volume of above-ground wood since this is the usual indicator measured and controlled by forest managers (Härtl et al. 2017). While $g_{t}$ is calculated as the difference in the stand's carbon stock after harvest at time $t-1$ and before harvest at time $t, u_{t}$ is calculated as follows. Harvested trees are turned into different wood products (e.g., fuelwood, construction materials) with different lifetimes and the carbon stored in these products is thus emitted at different points in time. We calculate the average lifetime of a tree as a function of its diameter (Online Resource 1, Table ESM4) based on the fractions of stem wood and industrial wood (including felling residues like tops, branches) that go into different product classes for Germany and the average lifetimes of each product class (Pistorius et al. 2006) (Online Resource 2, Table ESM3).

Periodic emissions of a harvest event are:

$$
u_{t}=\sum_{i=0}^{n} \frac{\operatorname{Carb}_{i}}{L T_{i}} * 5
$$

where Carb ${ }_{i}$ is the carbon sequestered in a harvested tree's ( $i$ ) above-ground biomass at time $t$. Following Härtl et al. (2017), we assume a linear decay of the carbon in wood products over their lifetime $L T_{i}$; thus, in every time period $t \mathrm{Carb}_{i} / L T_{i}$ tons of carbon are emitted for a single tree until all $C a r b_{i}$ is emitted. The periodic emissions at time $t, u_{t}$, are composed of the periodic emissions of the current and the preceding harvest events. 


\subsection{Creating scenarios to sample uncertainties}

To quantify the (relative) impact of climate change, timber price, discount rate, and model parameter uncertainty on the performance of the management strategy, we first sample these uncertainties. We construct this sample by crossing a number of selected samples from the uncertain factors as explained below.

We create model parameter scenarios adopting a precalibration approach to identify model parameter combinations that fit the observations reasonably well. Precalibration is a wellestablished and well-tested approach to identify model parameter samples that are broadly consistent with the observational constraints (Edwards et al. 2011). Precalibration is conceptually simpler than more refined methods, but can provide a useful starting point, especially in the face of complex and deeply uncertain observation errors and model structural errors (e.g., Ruckert et al. (2017)). Similar to related approaches such as the GLUE method (Beven and Binley 1992), precalibration uses a simplified metric to define the set of acceptable parameter samples. We start by drawing 100,000 stratified random samples using Latin Hypercube sampling (McKay et al. 1979) from a range of model parameter values that have a RMSE in yearly stand volume growth that is maximum 5\% higher than the RMSE of the optimal parameter set in the optimization process described in Section 2.1.1. We run the model for each sample and calculate the current stand volume growth $\left(\mathrm{m}^{3} / \mathrm{ha} / \mathrm{year}\right)$. We select all scenarios that lead to a maximum deviation of $3 \mathrm{~m}^{3} / \mathrm{ha} /$ year from the observed current volume growth as a sample of model parametric uncertainty.

Climate change scenarios are created based on 20 climate forecasts that result from 5 climate models, sampling the published representative concentration pathways (RCP) scenarios (2.6, 4.5, 6.0, and 8.5) (Meinshausen et al. 2011), taken from The Inter-Sectoral Impact Model Intercomparison Project (ISIMIP2) Fast Track project (details in Table 1). We turn the daily temperature $\left({ }^{\circ} \mathrm{C}\right)$ and precipitation $(\mathrm{mm})$ data into 6-year averages for every 5 th year (according to the simulation pattern of the forest model) and calculate the drought index and degree day index as climatic input variables for the forest model (see Section 2.1) according to Trasobares et al. (2016).

Timber price and discount rate scenarios are calculated by fitting an Autoregressive Integrated Moving Average model (ARIMA) time series model to observations (see Table 1). We use the ARIMA estimation and simulation function from R's forecast package (Hyndman and Khandakar 2008). ARIMA models are statistical models for analyzing and forecasting time series data that approximate the observed temporal structures. The statistical model assumes stationarity. We choose the ARIMA model type by running the automated ARIMA function from the forecast package which searches over possible models and returns the best ARIMA model according to different goodness-of-fit criteria. We verify the model choice using the (partial) auto-correlation function plots. We use the ARIMA to simulate ten forecast scenarios. Since we have no access to long-term records of timber prices for different assortment classes (see Section 2.1.2), we use a price index with base year $2010(2010=100)$ (Statistisches Bundesamt 2019) for scenario creation which is available for more than 50 years into the past. From these price index scenarios, we derive the actual changes in timber prices.

\subsection{Measuring robustness}

There are three main approaches for measuring the robustness of a strategy: (i) satisficing metrics, (ii) regret metrics, and (iii) descriptive statistics of the distribution of model outcome 
Table 1 Uncertainties considered for endogenous model parameter uncertainty and exogenous forcings and their depiction. Abbreviations: SE, standard error; ARIMA, autoregressive integrated moving average model; ISIMIP2, The Inter-Sectoral Impact Model Intercomparison Project; $R C P$, Representative concentration pathway

\begin{tabular}{|c|c|c|c|}
\hline Uncertainty & Scenario creation method & $\begin{array}{l}\# \\
\text { scenarios } \\
\text { selected }\end{array}$ & Source \\
\hline $\begin{array}{l}\text { Forest growth } \\
\text { model } \\
\text { parameters }\end{array}$ & $\begin{array}{l}\text { Selection of scenarios with an acceptable deviation } \\
\text { from observation. Scenarios created by stratified } \\
\text { sampling of } \pm 5 * \text { SE of original parameterization }\end{array}$ & 84 & Precalibration, this study \\
\hline $\begin{array}{l}\text { Climate futures } \\
\text { (drought } \\
\text { index) }\end{array}$ & $\begin{array}{l}\text { Calculation of drought index and degree day index } \\
\text { based on precipitation and temperature forecasts by } 5 \\
\text { global climate models with RCP scenarios } 2.6,4.5 \text {, } \\
6.0 \text {, and } 8.5 \text { each extracted for lon }=9.30, \text { lat }=49.42 \\
\text { (study stand). Global climate models: } \\
\text { GFDL-ESM2M, HadGEM2-ES, IPSL-CM5A-LR, } \\
\text { MIROC-ESM-CHEM, NorESM1-M }\end{array}$ & 20 & $\begin{array}{l}\text { ISIMIP2 Fast Track } \\
\text { project (Hempel et al. } \\
\text { 2013) }\end{array}$ \\
\hline Timber price & $\begin{array}{l}\text { Simulations from fitted ARIMA }(1,0,0) \\
\text { model to timber price index (averaged over species and } \\
\text { products) } 1967-2019\end{array}$ & 10 & $\begin{array}{l}\text { Statistisches Bundesamt } \\
\text { (2019) }\end{array}$ \\
\hline Discount rate & $\begin{array}{l}\text { Simulations from fitted ARIMA }(2,0,3) \text { model to real } \\
\text { interest rates on household deposits } 1967-2019\end{array}$ & 10 & $\begin{array}{l}\text { Deutsche Bundesbank } \\
\text { (2019) }\end{array}$ \\
\hline
\end{tabular}

over all scenarios (see McPhail et al. (2018) for an overview). To evaluate the robustness of the static management strategy under uncertainty, we choose the "satisficing" robustness approach (Hall et al. 2012), as it focuses on meeting the decision-makers' minimum performance requirements. A strategy is robust if it performs satisfactorily over many plausible future scenarios. Minimum performance requirements are set for the management objectives and in the more scenarios these requirements are met, the more robust a decision alternative is. We set minimum performance requirements using a "break-even" perspective for the NPV and a net carbon sequestration of at least zero. This means no net economic losses and carbon sequestration equals out the emissions from management.

We consider cases with and without a monetary compensation for the additional carbon sequestration. To showcase what effect the introduction of such a carbon policy might have on the robustness of the management strategy, we contrast a range of carbon taxes with robustness. Offering a revenue for carbon sequestration may level out a negative NPV of timber yield. The degree of robustness is measured as the fraction of scenarios in which the NPV, composed of discounted revenues from timber yield and carbon sequestration, is positive. This NPV is calculated for 241 carbon tax scenarios over a range of $[0,120]$ Euro per ton carbon sequestered.

\subsection{Sobol global sensitivity analysis}

We perform a global sensitivity analysis to rank the relative impact of uncertainties on the performance of objectives. This serves as a basis for identifying potential signposts for adaptation. We use the Sobol sensitivity analysis as developed by Sobol" (2001) and extended by Saltelli (2002) and Janon et al. (2014). The Sobol sensitivity analysis decomposes the variance in a model response into fractions attributable to the individual uncertain factors (both model parameters and forcings). We run the sensitivity analysis for the two objectives 
separately. We attribute the variance in NPV of timber yield to model parameter, climatic (drought index), timber price, and discount rate uncertainty and the variance in net carbon sequestration to model parameter and climatic uncertainty. We do not look at the impact of the model parameters individually but at the total model impact on the objectives' variance. We report first-order and total sensitivity indices. First-order Sobol sensitivity indices calculate the direct influence of each uncertainty (model and exogenous forcings) on the projected objectives. Total sensitivity indices additionally take into account the influence of interactions between the uncertainty terms (Sobol" 2001). We use stratified random sampling (Latin hypercube) to sample uniformly from the scenario ensemble (scenarios created in Section 2.2). For the net carbon sequestration sensitivity, we only take the ensemble of model parameter and climate parameter scenarios into account. Latin hypercube samples over a range of $[0,1]$. Each sample is then matched to a scenario according to an interval of 1 divided by the number of scenarios for the uncertain factor; e.g., a sample value of 0.01 is matched to scenario 1 (out of 10 timber price scenarios) and 0.9 matched to scenario 10.

We select 700 bootstraps samples from this sample to estimate the confidence intervals for the sensitivity indices. The estimated confidence intervals are all smaller than $10 \%$ of the largest total sensitivity index. Following previous work (Wong and Keller 2017), we interpret this as an indication that increasing the sample size for the Sobol analysis is not a high priority.

\subsection{Identifying potential signposts}

The Sobol analysis identifies key uncertainties, i.e., those that have a critical impact on the strategy's performance. A prerequisite for tracking is a signpost's observability (Garner and Keller 2018; Haasnoot et al. 2015; Raso et al. 2019), i.e., how easily its development is observable and how easily we can obtain observational data. We choose the key uncertainties and evaluate qualitatively whether their metrics could serve as signpost parameters or whether a proxy is needed. The uncertain factor can be the signpost itself, if it is directly observable (Raso et al. 2019). Otherwise, one can choose an observable proxy that represents the impact of the uncertain factor and at the same time has an effect on the management objective(s).

\section{Results}

\subsection{Model adaptation}

The model's fit to observational data is considerably improved by adapting the forest model's management module and optimizing the model parameters (Fig. 2), cutting the RMSE between observed and simulated data in about half (Online Resource 1, Table ESM1). We find 84 model parameter scenarios with an acceptable deviation in current stand volume growth from observed data. The current stand volume growth of the acceptable model parameter scenarios and the best fit scenario deviate less than the maximum acceptable bound of $\pm 3 \mathrm{~m}^{3} /$ ha/year from observed data and largely follows the same pattern. There is a single outlier at age 83 and we increased the acceptable deviation to $6 \mathrm{~m}^{3} /$ ha/year at this point in order to yield a set of acceptable model parameter scenarios. 


\subsection{Scenario creation}

The span of temperature and precipitation projections by different global climate models for different RCPs (Online Resource 1, Figures ESM1 and ESM2) translate to strong divergences in the drought index (the climate forcing for the adopted beech growth model) (Online Resource 1, Figure ESM3). The gap between the different scenarios increases with an increasing time horizon: While some scenarios predict low index values that suggest a strong limitation of the site productivity by drought, other scenarios remain close to 1 which means there is no limitation on site productivity by drought. Noticeably, the recorded climate data translates to a periodically low drought index, suggesting that there have been strong limitations on site productivity by drought already in the past 60 years.

We fit an ARIMA $(2,0,3)$ and an ARIMA $(1,0,0)$ model to the discount rate and timber price index time-series data, respectively (scenario results see Online Resource 1, Figure ESM3). The discount rate scenarios have a broad span with most scenarios rotating between -2 and $2 \%$. The strong downward trend into the negative discount rates does not continue for any scenario. The projections, mirroring the past, show strong oscillations for each scenario over time. Timber price scenarios include both upward and downward-trending scenarios. Prices may double compared to the 2010 reference level and at the other end, they can decrease to about half the reference price or even lower in a few periods.

\subsection{Robustness of the static management strategy}

We calculate the strategy's performance under 168,000 scenarios which result from enumerating all the model forcings and parameter scenarios (Table 1). We find that both objectives vary strongly under the considered uncertainties (Fig. 3). The NPV of timber ranges between about -7000 and 29,400 Euro/ha over the period from stand age of 63 to 123 years, thus from unviable to highly profitable. The distribution of NPV timber yield is unimodal, asymmetric, and left skewed. Ninety percent of the scenarios yield an NPV below about 10,700 Euro/ha; thus, few scenarios suggest a very high profit. The distribution of the net carbon sequestration is multimodal, remains positive under all scenarios, and ranges from about 80 to $200 \mathrm{t} \mathrm{C} / \mathrm{ha}$. The high variability in the two objectives alone does not mean that the current static management strategy is vulnerable (not robust), according to our definition of robustness. Indeed, the strategy satisfices the carbon sequestration minimum requirements under every scenario (Fig. 3). However, an economic breakeven is only reached in about $76 \%$ of the scenarios which means the current management strategy is not very robust and thus susceptible to uncertain future conditions.

However, we run a thought experiment and introduce a carbon tax that compensates for additional carbon sequestered. Figure 4 shows that a carbon tax of around 25 Euro per ton carbon can compensate for a negative NPV from timber yield in about $95 \%$ of the scenarios, thus increasing robustness substantially. The trade-off curve between robustness and carbon tax levels out at around 75 Euro/t $\mathrm{C}$ where an additional raise in carbon tax has only a marginal positive effect on overall robustness.

\subsection{Potential signposts}

Recall that the global sensitivity analysis quantifies the relative contribution of each uncertainty on the total variance for the two objectives. A high total order sensitivity indicates a 


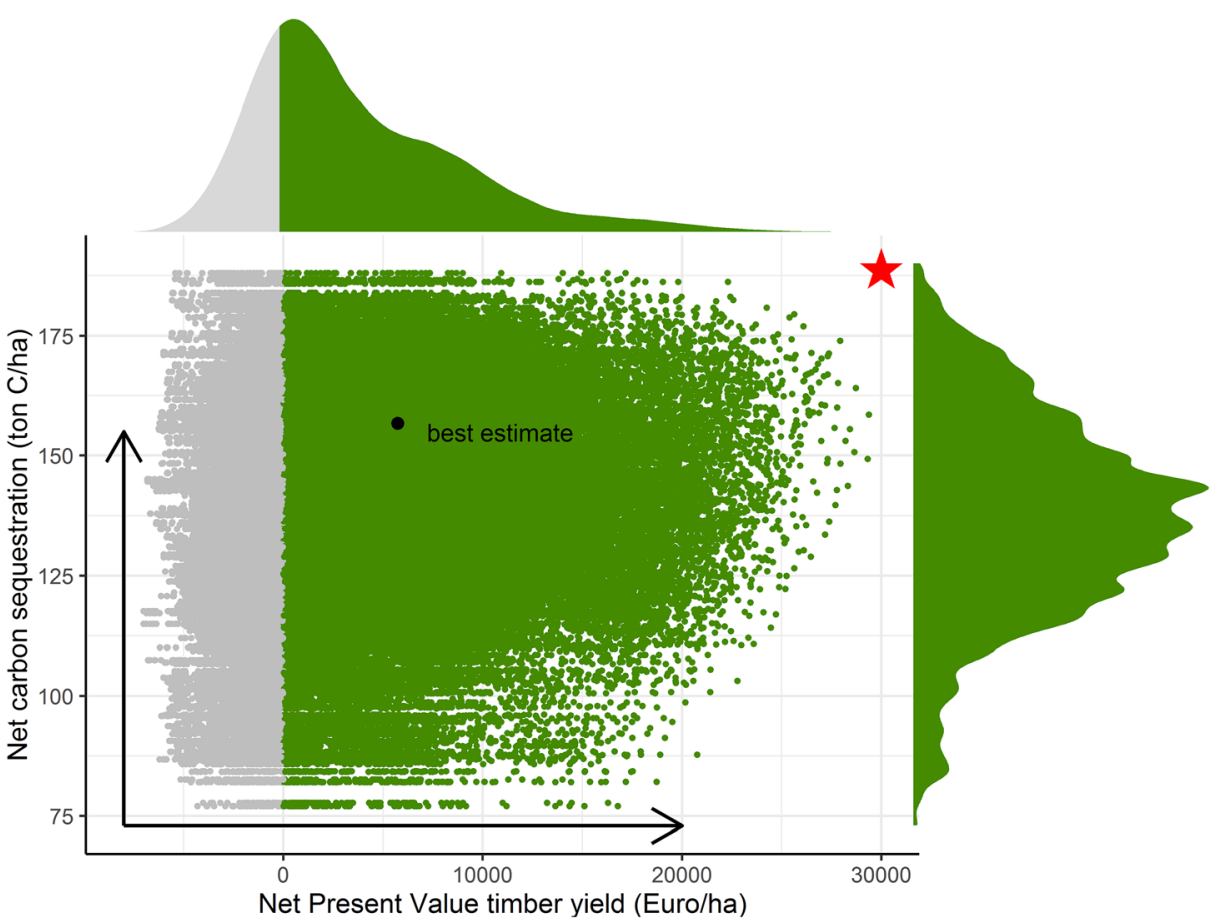

Fig. 3 Trade-offs between NPV of timber yield and net carbon storage (in above-ground biomass and timber products) between stand age 63 and 123 years under each of the 168,000 scenarios (composed of model parameters, climate, timber price, and discount rate) and their distribution. The black dot denotes the outcome under a best estimate scenario (best-guess model parameter scenario and mean timber, climate, and discount rate scenarios). Scenarios that meet the minimum requirements (NPV $>0$, net carbon sequestration $>0$ ) are shown in green and those that fail are colored in gray. The ideal outcome is indicated by the red star. The arrows indicate the preferred direction of the objectives

potentially important factor determining the robustness of the considered strategy. The results show that the values of the 1 st and the total order sensitivity indices only barely differ (Online Resource 1, Figure ESM4). This indicates a very weak interaction among the uncertainties. The variance in NPV of timber yield is mainly driven by economic uncertainties, especially by the discount rate, while the climatic uncertainty has a negligible impact, at least in relative terms (Table 2). In contrast, climatic uncertainty is responsible for most of the variance in net carbon sequestration. Perhaps surprisingly, the uncertainty surrounding the beech growth model has a small impact on both objectives.

Given their critical impacts on the objectives, the observable discount rates and drought indices are promising candidates to observe and to define signposts for. Both variables are directly observable (Table 2), so the signpost can be designed as a function of the real discount rate, and observed temperature (Online Resource 1, Figure ESM2) and precipitation rates (Online Resource 1, Figure ESM1). Nevertheless, their usefulness as signposts needs further testing.

As Haasnoot et al. (2015) point out, signposts are usually close to the metrics of the objectives, in our case NPV of timber yield and net carbon sequestration. Especially in the case of climate uncertainty, signposts may be more useful if they relate to the impacts as opposed to the forcings, for example, a metric directly influencing the carbon sequestration as opposed to 


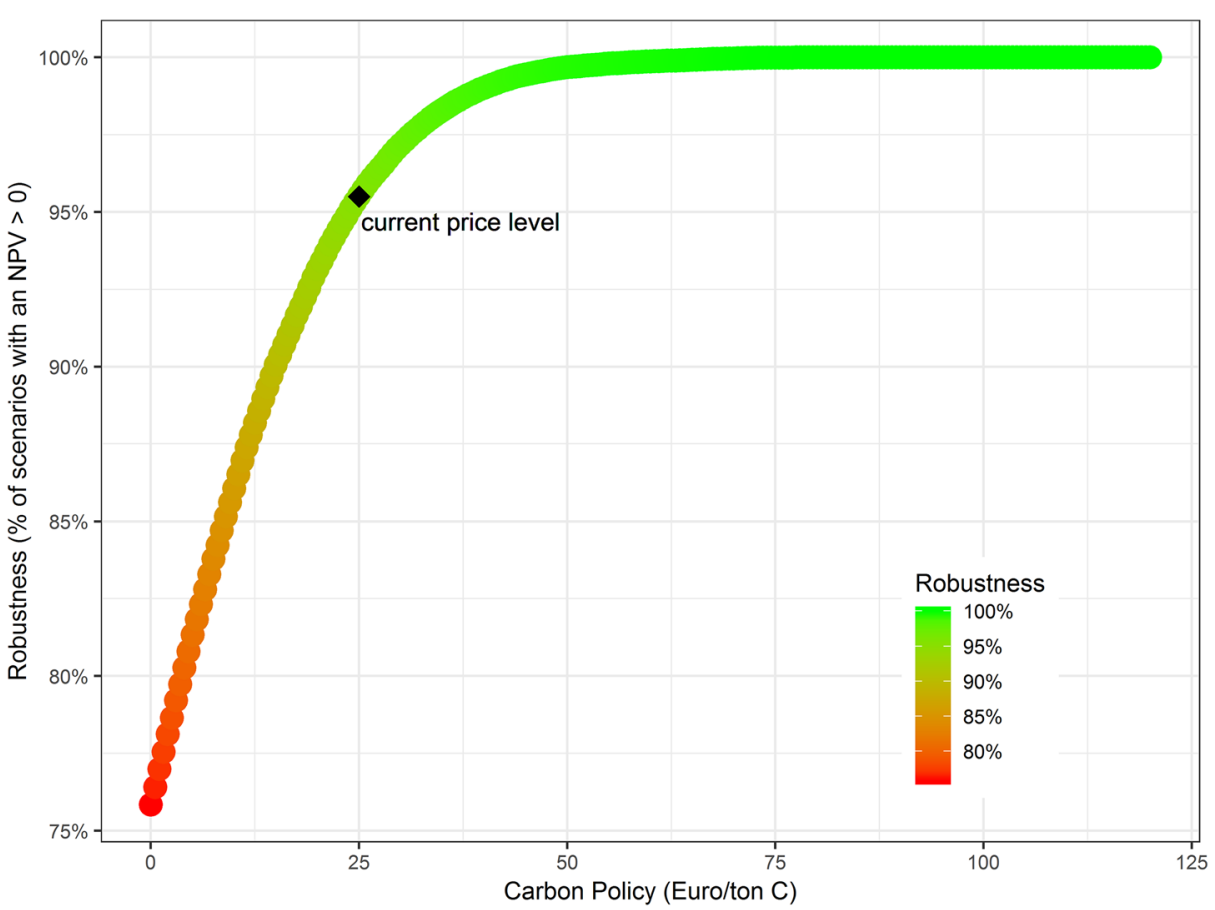

Fig. 4 Trade-off curve of introducing a carbon policy with a certain carbon tax per ton additionally sequestered carbon (in above-ground biomass and timber products over stand age 63-123 years) and the resulting robustness (percentage of scenarios where NPV $>0$ ) of the business-as-usual management strategy where NPV is the discounted revenues from timber yield and carbon sequestration. Current price level as of January 17, 2020

more indirectly linked variables such as climate itself (e.g., the drought index). One approach to implement and test this is to define a signpost in terms of above-ground tree volume growth over a reasonably long time period, which directly impacts both NPV of timber yield and net carbon sequestration. While temperature and precipitation show a sizable variability (see Online Resource 1, Figures ESM1, and ESM2) that can lead to false-positive signals, longer term trends in above-ground stand volume may send a clearer signal of the impact on our objectives. Forest inventories are conducted on a regular basis (usually every 10 years in Germany) and can thus provide information on the stand's volume growth. These values can

Table 2 Usefulness of uncertainties as potential signposts according to their (rounded) relative impact (totalorder Sobol indices) on NPV of timber yield and net carbon sequestration, whether the uncertainty can be directly observed and if not and what could be a potential proxy for the uncertainty

\begin{tabular}{|c|c|c|c|c|}
\hline \multirow[t]{2}{*}{ Uncertainties } & \multicolumn{2}{|c|}{ Impact on performance } & \multirow{2}{*}{$\begin{array}{l}\text { Direct } \\
\text { observability }\end{array}$} & \multirow[t]{2}{*}{ Potential proxy } \\
\hline & $\begin{array}{l}\text { NPV } \\
\text { timber }\end{array}$ & $\begin{array}{l}\text { Net carb. } \\
\text { seq. }\end{array}$ & & \\
\hline Drought index & $7.21 \%$ & $84.05 \%$ & Yes & 10 -year stand volume growth $\left(\mathrm{m}^{3} / \mathrm{ha}\right)$ \\
\hline $\begin{array}{l}\text { Timber price } \\
\text { index }\end{array}$ & $22.54 \%$ & / & Yes & $\begin{array}{l}\text { Current timber price (averaged over } \\
\text { assortments) }\end{array}$ \\
\hline Discount rate & $68.48 \%$ & / & Yes & l 1 - n \\
\hline $\begin{array}{l}\text { Model } \\
\text { parameters }\end{array}$ & $8.67 \%$ & $16.51 \%$ & No & 10 -year stand volume growth $\left(\mathrm{m}^{3} / \mathrm{ha}\right)$ \\
\hline
\end{tabular}


also be used for updating model parametrization, since stand volume development over time is a model output that reflects the whole bandwidth of model parameter uncertainties (diameter and height growth, mortality functions) and can be compared to the observed volume increment. Past volume increment can thus serve as a signpost for both climate and model parameter uncertainty. Change in drought index results in almost the same change in the corresponding volume increment over different time steps and uncertainty scenarios (Fig. 5). The correlation between the two signposts is close to one (black line). As a result, using both signals as signposts would be partially redundant. This is consistent with the discussion in Raso et al. (2019) regarding parsimony: Not every critical uncertainty needs a separate signpost if the uncertainties do not need to be distinguished for taking an adaptation action.

\section{Discussion}

The key objectives of this paper are to (i) illustrate how existing methods can be transferred to inform robust decision-making in a forest management decision problem, (ii) gain insights into decision-relevant uncertainties and potential signposts, and (iii) provide a novel test case for robust decision-making methods. We discuss below (i) the methods transfer to forest management and (ii) lessons learned from applying the methods to our case study. We also address the limitations and open research needs.

\subsection{Model parametric uncertainty}

Model parameter uncertainty is often disregarded when quantifying the impact of overall uncertainties in forest management despite its relevant role (Augustynczik et al. 2017; Reyer

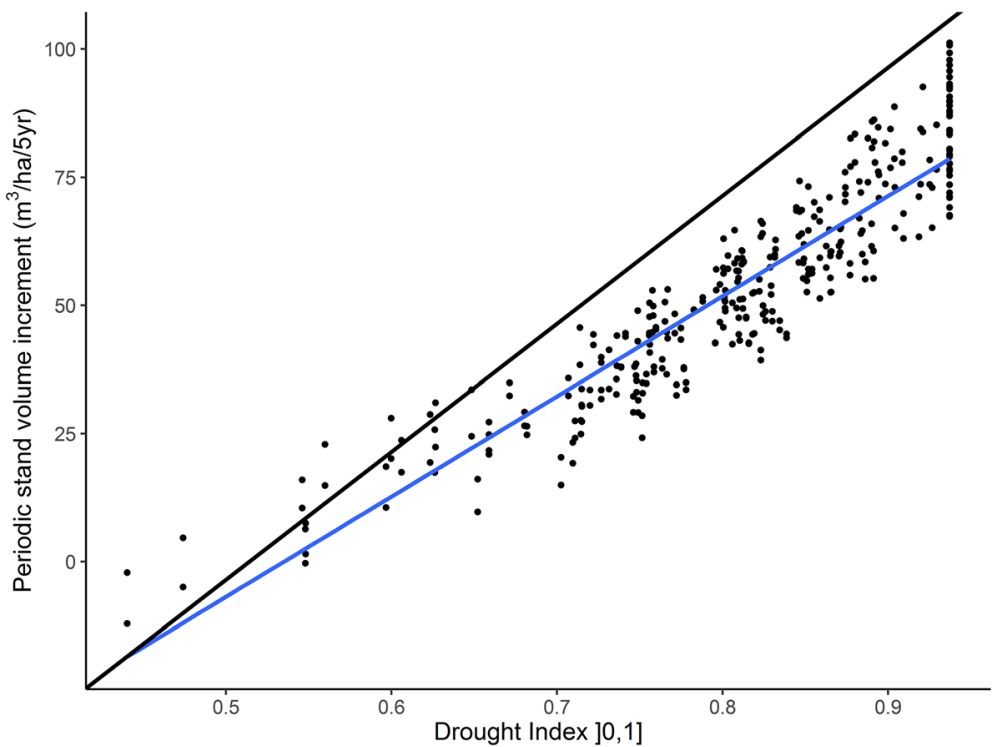

Fig. 5 The two potential signposts (past stand volume increment and drought index) show a high correlation (blue linear regression line). The black line denotes a hypothetical correlation of one. Each point is a simulation of a 5-year stand volume increment given a drought index for different time steps and scenarios (climate, model parameter) 
et al. 2016). We use precalibration to derive model parameter uncertainty, i.e., model parameter combinations that have an acceptable fit. Our uncertainty representation could be improved by complementing precalibration prior to search with data from the literature as in Augustynczik et al. (2017) who used Bayesian calibration to fit the model and validation data to calculate model parameter uncertainty.

\subsection{Scenario selection for exogenous uncertainties}

The results of the robustness and the sensitivity indices are highly dependent on the scenario choices, namely which scenarios are picked, on which basis they are created, and which priors were chosen. We select these exogenous uncertainties based on our perceived importance for the decision and on the availability of data to create scenarios. At the same time, there are, of course, other uncertainties that might have an impact on forest management decisions such as the market demand and policies that pose requirements. Also, changes in wood characteristics, when trees adapt to climate change and diseases, may have an impact. Some uncertainties cannot be included due to the limitations of the model: The occurrence and impact on disturbances and pests, for example, are not accounted for in this adopted beech growth model. While the general practice in forest science represents discount rate uncertainty by rates that remain constant over time, e.g., 1-5\% scenarios (e.g., Augustynczik et al. (2017)), or more recently also declining discount rates (Knoke et al. 2017), we choose to fit a time series model and make simulations in order to account for variations of the discount rate over time. This technique has previously been applied by Newell and Pizer (2003). Their study uses simulations from a time series model fitted to historical bond data to calculate a certaintyequivalent rate. Very untypically to common practice in discounting, we also choose scenarios that include negative discount rates. These imply that future cash flows are valued higher than present cash flows. The negative discount rates result from the fact that the negative real interest rate on household deposits for Germany has stayed negative since 2010. While we fit a time series model and sample predictions from this model, other studies that represent timber price uncertainty mainly stick to random draws from a fitted distribution (Augustynczik et al. 2017) or Monte Carlo simulations (Messerer et al. 2017; Roessiger et al. 2011) that also rely on random picks from recorded data. We derive price scenarios based on a timber price index that represents the price development averaged over all timber products and tree species in Germany. We choose this index as it has a long record, in contrast to pure beech prices that have no homogeneous long-term record. Since deciduous and coniferous timber prices have different variation patterns, this timber price index is not perfectly fit for beech price uncertainty, but is used in this study to showcase the scenario creation method. We focus on the drought index as an indicator of climatic uncertainty. Since the precipitation and temperature scenarios all lead to the same degree-day index value, there is no need to include this indicator as an uncertainty.

\subsection{Robustness of static thinning plan}

We define a robust strategy as one that satisfies minimum performance requirements in as many of the plausible future states as possible. Intuitively, robustness is often understood as minimizing the performance variance (Hamarat et al. 2014). Our results illustrate that a highly variable performance does not necessarily imply non-robustness: Variance can also be positive as it shows that performance can be improved under specific scenarios. Both objectives can be 
largely improved compared to their best estimate performance. The projected net carbon sequestration is positive over all scenarios which is partially due to the high amount of carbon that is stored over long times in wood products. Robustness is highly dependent on how the preferences and minimum performance requirements regarding management objectives are allocated (Radke et al. 2017). Here, we define that both objective metrics need to be positive, so that the strategy is both economically profitable and has no negative carbon effect. While these settings lead to a relatively low robustness, a more carbon-oriented management would potentially accept a negative NPV of timber yield and might therefore be fully robust in our example. In turn, a market-oriented management that aims at profits beyond a breakeven would have a considerably lower robustness. It is insightful to consider how different levels of a policy could improve robustness. Here, the introduction of a carbon tax, even below the current carbon price level, could improve robustness by weighing out a negative NPV of timber yield by incomes from carbon sequestration. While we use a "satisficing" robustness approach as described earlier, in reality, different robustness metrics exist, e.g., regret-based and other satisficing-based (see McPhail et al. (2018) for an overview) that can lead to very different robustness outcomes (Hadka et al. 2015; Herman et al. 2015). The satisficing robustness approach we chose is highly suitable when a decision is tied to minimum performance requirements that need to be fulfilled. The choice of metric should thus be dependent on the decision context. Analyzing the robustness under different metrics can be insightful, too, and can help understand the decision context better (Herman et al. 2015; Hadka et al. 2015).

We analyze a simple and parsimonious set of objectives that span economic and ecological considerations. In reality, forest management decisions often encompass more objectives relating to additional forest functions and services such as biodiversity conservation and recreation (see Blattert et al. (2017) for a review on relevant objectives and indicators). The methods we apply here are restricted to objectives that can be derived from the model output. Generally, it is possible to expand the model and define metrics for objectives from a variety of domains as shown by Blattert et al. (2017). This may lead to a more complete picture of a typical forest management decision problem. Although it is possible to take into account multiple outputs in the analysis, it should be noted that $t$ decision-makers can struggle with successfully navigating high dimensional objective spaces (Oprean et al. 2019).

\subsection{Decision-relevant uncertainties and potential signposts}

The relative sensitivities of the uncertain factors provide a basis for evaluating their potential as signposts for adaptation.

While the relative importance of discount rate and model parameter sensitivities in the case study are in line with observations from other studies (e.g., Augustynczik et al. (2017)), the behavior of the climatic sensitivity is perhaps more surprising. While the climate change metric has a negligible impact on economic performance, it has a dominant impact on carbon sequestration. This is not immediately obvious, as both the economic and the carbon performance metrics depend on the harvested volume. Yet, the carbon sequestration also depends on the amount of harvested carbon that is stored in different wood product classes, which can at least at first glance explain this phenomenon.

We pick those uncertainties that crucially impact the strategy's performance and translate them to metrics that are observable and give clear signals. While we do a computationally somewhat involved global sensitivity analysis and check observability and parsimony in a 
qualitative, intuitive way, other studies elicit signposts in more or less depth. Generally, they are based on expert judgments and sometimes on scenario discovery or other vulnerability analysis but there often is no systematic approach (Haasnoot et al. 2015; Raso et al. 2019).

Choosing a signpost that can be easily related to a system's state, e.g., growth in the stand's volume can be related to the volume that should be harvested, is required for some dynamic robust decision approaches. This is demonstrated, for example, by Garner and Keller (2018) in their application of Dynamic Policy Search for dike height decisions under uncertain changes in local sea levels. A criterion for signpost selection which we were silent on here is the ability to detect its change on time (Raso et al. 2019) and without giving false-positive alarms for adaptation (Haasnoot et al. 2015). This is especially a challenge for extreme events such as wind throws by storms that have an immense impact on the stand's performance while at the same time its rarity reduces the capacity to observe such events. These rare but high-risk events are not accounted for in this forest model and thus are out of scope for this study.

A recommended next step before implementing a DAS is to evaluate the monitoring system as a whole for its completeness, redundancies, and synergies (Raso et al. 2019). Also, triggers need to be elicited i.e. critical values of the observed signpost metrics that signal when to adapt. Triggers can be elicited by identifying areas of the uncertain factors that lead to vulnerabilities or opportunities (see Kwakkel and Haasnoot (2019)).

\section{Conclusions}

The multi-objective nature of forest management in the face of multiple deep uncertainties, including climatic change, poses non-trivial decision-problems. In this case, guidance on how to account for and deal with these uncertainties can be rather useful. Forest management is commonly based on static plans over a stand's rotation period which are susceptible to failure if the future turns out different than expected. Dynamic adaptive robust decision-making approaches provide methods that identify and track decision-relevant uncertainties to adapt the current strategy when needed with the potential for improved performance. They have found successful application in other fields of natural resources management under deep uncertainties. This paper now introduces a set of these methods for identifying decisionrelevant uncertainties and potential signposts to forest science. Signposts signal the need for adapting the current strategy so that it becomes dynamic and adapts to new knowledge. This work thus advances dynamic, adaptive robust decision-making in the field of forest management by showcasing how existing methods can be translated to a case study of forest management under climatic, economic, and model uncertainties at the stand level. The case study results exemplify how a strategy's robustness can be tested and provide insights into the relative importance of climatic uncertainty compared to other uncertainties. On that basis, it discusses potential signposts for adaptation. While the considered strategy is especially vulnerable to economic uncertainties, our analysis suggests ways how the introduction of a carbon policy can improve its robustness. Perhaps surprisingly, climatic uncertainty strongly influences carbon sequestration objectives, while it has a negligible impact on the NPV of timber yield. As the uncertain economic factors are easily traceable, they are obvious candidates for signposts. The stand's current volume growth is another promising signpost that captures well the effects of climate change without giving false positive signals. It is a key metric tracked during the regular inventory and planning cycles. This established system thus offers a promising basis for DAS that are regularly evaluated. This work provides a foundation 
for further evaluating the usefulness of the proposed signposts for detecting adaptation need to climatic and economical changes and for adopting DAS to a forest management context.

Author contributions All authors contributed to the study conception and design. Material preparation, data collection, and analysis were performed by N.R. The first draft of the manuscript was written by N.R. and R.Y. K.K. and M.H. commented on previous versions of the manuscript. All authors read and approved the final manuscript.

Funding Open Access funding enabled and organized by Projekt DEAL. This research was co-supported by the US National Science Foundation through the Network for Sustainable Climate Risk Management (SCRiM) under NSF cooperative agreement GEO-1240507 as well as the Penn State Center for Climate Risk Management under Award Number 1617396.

\section{Compliance with ethical standards}

Conflict of interest The authors declare that they have no conflicts of interest.

Disclaimer Any opinions, findings, and conclusions or recommendations expressed in this material are those of the authors and do not necessarily reflect the views of the funding entities.

Data and code availability Data and code are available under a GNU general public license at https://github. com/NaomiRadke/robustness_sensitivity_analysis. The repository provides all code and data with exception of the beech growth model's (Trasobares et al. 2016) source code and confidential beech stand data (by the Forest Research Institute of Baden-Württemberg).

Open Access This article is licensed under a Creative Commons Attribution 4.0 International License, which permits use, sharing, adaptation, distribution and reproduction in any medium or format, as long as you give appropriate credit to the original author(s) and the source, provide a link to the Creative Commons licence, and indicate if changes were made. The images or other third party material in this article are included in the article's Creative Commons licence, unless indicated otherwise in a credit line to the material. If material is not included in the article's Creative Commons licence and your intended use is not permitted by statutory regulation or exceeds the permitted use, you will need to obtain permission directly from the copyright holder. To view a copy of this licence, visit http://creativecommons.org/licenses/by/4.0/.

\section{References}

Altherr, E (1971) Wege zur Buchen-Starkholzproduktion. Bericht 15. Hauptversammlung des BadenWürttembergischen Forstvereins und 100-Jahr-Feier der Baden-Württembergischen Forschungs- und Versuchsanstalt. FVA, Freiburg

Augustynczik ALD, Hartig F, Minunno F et al (2017) Productivity of Fagus sylvatica under climate change - a Bayesian analysis of risk and uncertainty using the model 3-PG. For Ecol Manag 401:192-206. https://oi. org/10.1016/j.foreco.2017.06.061

Beven K, Binley A (1992) The future of distributed models: model calibration and uncertainty prediction. Hydrol Process 6(3):279-298. https://doi.org/10.1002/hyp.3360060305

Blattert C, Lemm R, Thees $\mathrm{O}$ et al (2017) Management of ecosystem services in mountain forests: review of indicators and value functions for model based multi-criteria decision analysis. Ecol Indic 79:391-409. https://doi.org/10.1016/j.ecolind.2017.04.025

Deutsche Bundesbank (2019): Real interest rates on households' deposits. Edited by Deutsche Bundesbank. Available online at https:/www.bundesbank.de/en/statistics/money-and-capital-markets/interest-rates-andyields/real-interest-rates-on-households-deposits Accesed 1 Jan 2020

Edwards NR, Cameron D, Rougier J (2011) Precalibrating an intermediate complexity climate model. Clim Dyn 37(7-8):1469-1482. https://doi.org/10.1007/s00382-010-0921-0

Forst BW (2014) Richtlinie landesweiter Waldentwicklungstypen. ForstBW, Stuttgart 
Garner GG, Keller K (2018) Using direct policy search to identify robust strategies in adapting to uncertain sealevel rise and storm surge. Environ Model Softw 107:96-104. https://doi.org/10.1016/j.envsoft.2018.05.006

Haasnoot M, Kwakkel JH, Walker WE, ter Maat J (2013) Dynamic adaptive policy pathways. A method for crafting robust decisions for a deeply uncertain world. Glob Environ Chang 23(2):485-498. https://doi. org/10.1016/j.gloenvcha.2012.12.006

Haasnoot M, Schellekens J, Beersma JJ et al (2015) Transient scenarios for robust climate change adaptation illustrated for water management in the Netherlands. Environ Res Lett 10(10):105008. https://doi. org/10.1088/1748-9326/10/10/105008

Hadka D, Herman J, Reed P, Keller K (2015) An open source framework for many-objective robust decision making. Environ Model Softw 74:114-129. https://doi.org/10.1016/j.envsoft.2015.07.014

Hall JW, Lempert RJ, Keller K et al (2012) Robust climate policies under uncertainty. A comparison of robust decision making and info-gap methods. Risk Anal 32(10):1657-1672. https://doi.org/10.1111/j.15396924.2012.01802.x

Hamarat C, Kwakkel JH, Pruyt E, Loonen ET (2014) An exploratory approach for adaptive policymaking by using multi-objective robust optimization. Simul Model Pract Theory 46:25-39. https://doi.org/10.1016/j. simpat.2014.02.008

Hempel S. et al. (2013) Bias corrected GCM input data for ISIMIP Fast Track. GFZ Data Services, https://doi. org/10.5880/PIK.2016.001

Härtl F, Hahn A, Knoke T (2013) Risk-sensitive planning support for forest enterprises. The YAFO model. Comput Electron Agric 94:58-70. https://doi.org/10.1016/j.compag.2013.03.004

Härtl F, Höllerl S, Knoke T (2017) A new way of carbon accounting emphasises the crucial role of sustainable timber use for successful carbon mitigation strategies. Mitig Adapt Strat G1 22(8):1163-1192. https://oi. org/10.1007/s11027-016-9720-1

Herman JD, Reed PM, Zeff HB, Characklis GW (2015) How should robustness be defined for water systems planning under change? J Water Resour Plan Manag 141(10):4015012. https://doi.org/10.1061 /(ASCE)WR.1943-5452.0000509

Hyndman RJ, Khandakar Y (2008) Automatic time series forecasting. The forecast package for R. J Stat Soft 27 (3): 1-22. https://doi.org/10.18637/jss.v027.i03

Janon A, Klein T, Lagnoux A et al (2014) Asymptotic normality and efficiency of two Sobol index estimators. ESAIM: PS 18:342-364. https://doi.org/10.1051/ps/2013040

Kasprzyk JR, Nataraj S, Reed PM, Lempert RJ (2013) Many objective robust decision making for complex environmental systems undergoing change. Environ Model Softw 42:55-71. https://doi.org/10.1016/j. envsoft.2012.12.007

Knight FH (1921) Risk, uncertainty and profit. Martino Publishing, Mansfield Center

Knoke T, Paul C, Härtl F (2017) A critical view on benefit-cost analyses of silvicultural management options with declining discount rates. Forest Policy Econ 83:58-69. https://doi.org/10.1016/j.forpol.2017.06.005

Kublin E, Scharnagel G (1988) Verfahrens- und Programmbeschreibung zum BWI-Unterprogramm BDAT. FVA, Freiburg

Kwakkel JH (2017) The exploratory modeling workbench. An open source toolkit for exploratory modeling, scenario discovery, and (multi-objective) robust decision making. Environ Model Softw 96:239-250. https://doi.org/10.1016/j.envsoft.2017.06.054

Kwakkel JH, Haasnoot M (2019) Supporting DMDU: a taxonomy of approaches and tools. In: Marchau VAWJ, Walker WE, Bloemen PJTM (Eds.): Decision making under deep uncertainty. Springer, Cham. https://doi. org/10.1007/978-3-030-05252-2_15

Lempert R, Popper S, Bankes S (2003) Shaping the next one hundred years. New methods for quantitative, longterm policy analysis. RAND Corporation, Santa Monica

Lindner M, Fitzgerald JB, Zimmermann NE et al (2014) Climate change and European forests. What do we know, what are the uncertainties, and what are the implications for forest management? J Environ Manag 146:69-83. https://doi.org/10.1016/j.jenvman.2014.07.030

Marchau VAWJ, Walker WE, Bloemen PJTM (Ed.) (2019): Decision making under deep uncertainty. From Theory to Practice https://doi.org/10.1007/978-3-030-05252-2

McKay MD, Beckman RJ, Conover WJ (1979) A Comparison of Three Methods for Selecting Values of Input Variables in the Analysis of Output from a Computer Code. Technometrics 21(2):239

McPhail C, Maier HR, Kwakkel JH et al (2018) Robustness metrics. How are they calculated, when should they be used and why do they give different results? Earth's Future 6(2):169-191. https://doi.org/10.1002/2017 EF000649

Meinshausen M, Smith SJ, Calvin K et al (2011) The RCP greenhouse gas concentrations and their extensions from 1765 to 2300. Clim Chang 109(1-2):213-241. https://doi.org/10.1007/s10584-011-0156-Z 
Messerer K, Pretzsch H, Knoke T (2017) A non-stochastic portfolio model for optimizing the transformation of an even-aged forest stand to continuous cover forestry when information about return fluctuation is incomplete. Ann For Sci 74:1-16

Millar C, Stephenson NL, Stephens SL (2007) Climate change and forests of the future. Managing in the face of uncertainty. Ecol Appl 17(8):2145-2151. https://doi.org/10.1890/06-1715.1

Mullen K, Ardia D, Gil D et al (2011) DEoptim. An R Package for Global Optimization by Differential Evolution. J Stat Softw 40:1-26

Newell RG, Pizer WA (2003) Discounting the distant future. How much do uncertain rates increase valuations? J Environ Econ Manag 46(1):52-71. https://doi.org/10.1016/S0095-0696(02)00031-1

Oprean D, Spence C, Simpson M et al. (2019) Human interpretation of trade-off diagrams in multi-objective problems: implications for developing interactive decision support systems. In Proceedings of the $52^{\text {nd }}$ Hawaii International Conference on System Sciences (p. in the press). https://scholarspace.manoa.hawaii. edu/handle/10125/59596. Accessed 5 July 2020

Petr M, Vacchiano G, Thom D et al (2019) Inconsistent recognition of uncertainty in studies of climate change impacts on forests. Environ Res Lett 14(11):113003. https://doi.org/10.1088/1748-9326/ab4670

Pistorius T, Zell J, Hartebrodt C (2006) Untersuchungen zur Rolle des Waldes und der Forstwirtschaft im Kohlenstoffhaushalt des Landes Baden-Württemberg. FVA, Freiburg

Quinn JD, Reed PM, Keller K (2017) Direct policy search for robust multi-objective management of deeply uncertain socio-ecological tipping points. Environ Model Softw 92:125-141. https://doi.org/10.1016/j. envsoft.2017.02.017

Radke N, Yousefpour R, von Detten R, Reifenberg S, Hanewinkel M (2017) Adopting robust decision-making to forest management under climate change. Ann For Sci 74:1-16. https://doi.org/10.1007/s13595-017-0641-2

Raso L, Kwakkel J, Timmermans J, Panthou G (2019) How to evaluate a monitoring system for adaptive policies. Criteria for signposts selection and their model-based evaluation. Clim Chang 153:267-283. https://doi.org/10.1007/s10584-018-2355-3

Reyer CPO, Flechsig M, Lasch-Born P, van Oijen M (2016) Integrating parameter uncertainty of a process-based model in assessments of climate change effects on forest productivity. Clim Chang 137(3-4):395-409. https://doi.org/10.1007/s10584-016-1694-1

Roessiger J, Griess VC, Knoke T (2011) May risk aversion lead to near-natural forestry? A simulation study. Forestry 84(5):527-537. https://doi.org/10.1093/forestry/cpr017

Ruckert KL, Shaffer G, Pollard D et al (2017) Assessing the impact of retreat mechanisms in a simple Antarctic ice sheet model using Bayesian calibration. PLoS One 12(1):e0170052. https://doi.org/10.1371/journal. pone. 0170052

Saltelli A (2002) Making best use of model evaluations to compute sensitivity indices. Comput Phys Commun 145(2):280-297. https://doi.org/10.1016/S0010-4655(02)00280-1

Seidl R, Thom D, Kautz M et al (2017) Forest disturbances under climate change. Nat Clim Chang 7:395-402. https://doi.org/10.1038/NCLIMATE3303

Sobol' IM (2001) Global sensitivity indices for nonlinear mathematical models and their Monte Carlo estimates. Math Comput Simul 55(1-3):271-280. https://doi.org/10.1016/S0378-4754(00)00270-6

Statistisches Bundesamt (2019) Preise. Preisindizes für Land- und Forstwirtschaft, Destatis

Trasobares A, Zingg A, Walthert L, Bigler C (2016) A climate-sensitive empirical growth and yield model for forest management planning of even-aged beech stands. Eur J Forest Res 135(2):263-282. https://doi. org/10.1007/s10342-015-0934-7

Walker WE, Rahman SA, Cave J (2001) Adaptive policies, policy analysis, and policy-making. Eur J Oper Res 128(2):282-289. https://doi.org/10.1016/S0377-2217(00)00071-0

Wong TE, Keller K (2017) Deep uncertainty surrounding coastal flood risk projections. A case study for New Orleans. Earth's Future 5(10):1015-1026. https://doi.org/10.1002/2017EF000607

Yousefpour R, Jacobsen JB, Thorsen BJ et al (2012) A review of decision-making approaches to handle uncertainty and risk in adaptive forest management under climate change. Ann For Sci 69(1):1-15. https://doi.org/10.1007/s13595-011-0153-4

Publisher's note Springer Nature remains neutral with regard to jurisdictional claims in published maps and institutional affiliations. 


\section{Affiliations}

\section{Naomi Radke ${ }^{1} \cdot$ Klaus Keller $^{2,3} \cdot$ Rasoul Yousefpour $^{1} \cdot$ Marc Hanewinkel $^{1}$}

1 Forestry Economics and Forest Management, University of Freiburg, Tennenbacher Str. 4, 79106 Freiburg, Germany

2 Department of Geosciences, Penn State University, 217 Earth \& Engineering Sciences Building, University Park, PA 16802, USA

3 Earth and Environmental Systems Institute, Penn State University, 436 Deike Building, University Park, PA 16802, USA 